\title{
Temperature effects in the drilling of human and bovine bone
}

\author{
M.T. Hillery ${ }^{a, *}$, I. Shuaib ${ }^{\mathrm{b}}$ \\ ${ }^{a}$ Department of Manufacturing and Operations Engineering, University of Limerick, Limerick, Ireland \\ ' 'Izzak W. Killam Childrens' Orthopaedic Hospital, Halifax, NS, Canada
}

\begin{abstract}
Bone is an anistropic material, the drilling of which is an essential part of internal fixation in orthopaedic and trauma surgery. Some research has been carried out into the drilling of bone, but there are no definitive recommendations available on the most suitable drill shape or on the optimum drilling speed that should be used in surgical practice. The heat generated during the drilling of bone is proportional to the drilling speed and may be partially dissipated by the presence of blood and tissue fluids and also partially carried away by the chips formed. However, some heat may be conducted into the bone which, if exposed to a temperature higher than $55^{\circ} \mathrm{C}$, may sustain serious damage. This is important in orthopaedics, since most holes drilled are subsequently tapped for retaining screws. If the drill burns the bone to any great depth, the thread will not anchor properly and the fixation could work itself loose. This paper describes the drill design for accurate temperature measurement at the drill point and further shows that whilst the temperature may go to much higher than $55^{\circ} \mathrm{C}$ because of the poor conductivity of the bone the depth of damage is not critical insofar as screw fixation is concerned. (C) 1999 Elsevier Science S.A. All rights reserved.
\end{abstract}

Keywords: Drilling; Orthopaedics; Bone; Surgery; Temperature; Thermocouple; Sensor

\section{Introduction}

Bone is a special type of connective tissue consisting of inter-cellular calcified material. There are two types of bone, the outer hard layer that is called cortical bone and an inner spongy layer called cancellous bone. The outer surface of the bone is covered by a tough layer of osteogenic (boneforming) connective tissue called periosteum. Most of the inside of a bone is hollow and contains bone marrow. The inner surface of the bone is also lined with a similar cell layer with osteogenic properties called endosteum. Both the periosteum and the endosteum contain the bone vascular system which supply it with nutrients and oxygen for bone growth and repair. Bone fracture is a feature of everyday life due to accident or otherwise. When a bone is broken the periosteum and endosteum provide bone-forming cells, which endeavour to bridge the fracture. One of the principal methods of repair and reconstruction of a fracture is achieved by drilling the bone and fixing the separate parts together using screws, wires and plates. Fig. 1 shows a typical application of drilling in femoral fracture surgery.

Many problems are encountered when drilling bone in orthopaedic and trauma surgery such as hole accuracy, drill

*Corresponding author. Tel.: +353-61-202852; fax: +353-61-202913 E-mail address: michael.hillery@ul.ie (M.T. Hillery) wander (walking) and heat generation. Also, other unpredictable situations can occur due to the non-homogeneous structure of the bone material itself.

Many different drill-bit designs and geometries have been suggested over the years, [1-3], each with its own claim to success but most of them are based on conventional twistdrill geometry for the drilling of metals. The drills used are: twist drills, guide wires and large diameter drills/reamers.

\subsection{Implant and drill materials}

Implants must be made from corrosion-resistant materials. They mainly consist of $0.3 \%$ carbon, $17-19 \%$ chromium, 13-15\% nickel, 3\% molybdenum, 2\% manganese and up to $60 \%$ iron, with other trace elements.

Also, many of the plates and screws used in implant surgery are made from titanium, which, in its pure state, is bio-compatible and corrosion-resistant. There is little or no allergic reaction to it by adjacent tissue, thus allowing implants made from titanium to remain in the human body for long periods of time. There are ISO(5832-1), AISI (316L) and DIN (17-440) standards for implant materials.

Drill steels for orthopaedic procedures are not required to be as corrosion-resistant as implant materials, since they are not in contact with body fluids or tissue for long periods of time. It is much more important that they retain their cutting 


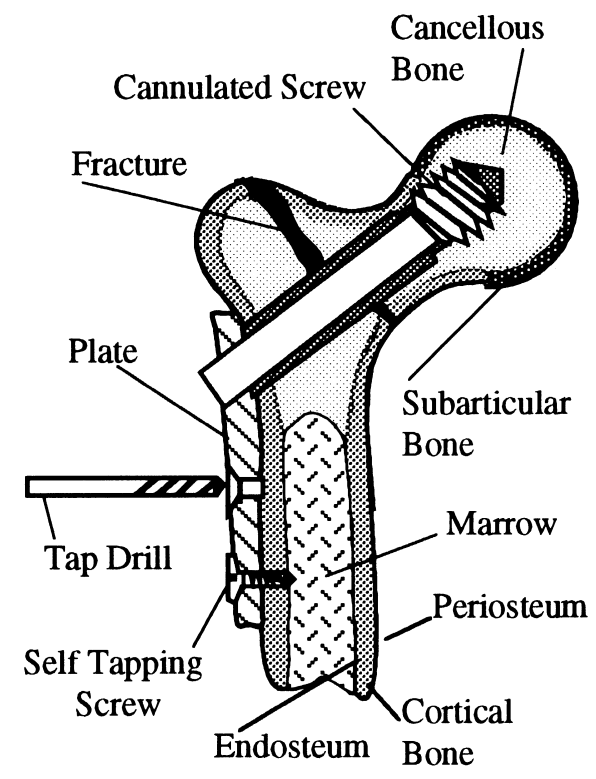

Fig. 1. Drilling of cancellous bone in femoral fracture surgery.

edge and withstand repeated sterilisation cycles in an autoclave at temperatures of up to $135^{\circ} \mathrm{C}$. They are manufactured to a standard such as DIN 1.4112 or AISI 440B and have chemical compositions of approximately $0.85 \% \mathrm{C}, 18 \% \mathrm{Cr}$, $1 \% \mathrm{Mo}, 1 \% \mathrm{Mn} 1 \% \mathrm{Si}$, and trace elements, with the remainder made up of iron.

\subsection{Fixation of bone}

In dynamic bone fixation there is some movement at the fracture site so that the load is shared by the implant and the bone, thus allowing the fracture to be subjected to stresses leading to rapid healing. This type of fixation allows for early joint mobilisation and reduces or prevents stiffness setting in on other joints. In many orthopaedic procedures holes of $3.2 \mathrm{~mm}$ diameter are drilled into the hard cortical bone where $\phi 4.5 \mathrm{~mm}$ self-tapping surgical screws are used for securing pieces of fractured bone, or implant plates or to anchor wires that are used for binding the pieces of bone together until new growth restores the fractures to their natural state. These screws, plates and/or wires may remain in position for several months. However, it is much more important that the repaired fracture, in the case of a lower limb, is strong enough to support the weight of the patient within hours of the operation. To ensure that this is the case the anchoring of the self-tapping screws has to be as close to perfect as possible.

\section{Heat generation when drilling bone}

Bone is a poor conductor of heat, with the thermal conductivity of fresh cortical bone in the region of 0.38 $2.3 \mathrm{~J} / \mathrm{msK}$ [4-6]. Heat generation is a common problem during any type of drilling but particularly during the drilling of bone due to the sensitivity of bone to heat damage and the difficulty of conducting heat away from the cutting edge, both as a result of the poor conductivity of the bone and the inability to use a coolant because of the danger of causing infection to the area.

However, some of the heat generated during drilling may be partially dissipated by the presence of blood and tissue fluids and partially carried away by the chips formed but the temperature rise at the cutting edge in a deep cortical hole could be significantly high. Lundskog [6] states that if bone is exposed for longer than $30 \mathrm{~s}$ at $50^{\circ} \mathrm{C}$ cellular necrosis will be induced. Mortiz and Henrique [7,8] established that when epithelial cells are exposed to a temperature of $70^{\circ} \mathrm{C}$ they will be damaged immediately, that when they are exposed to a temperature of $55^{\circ} \mathrm{C}$ for $30 \mathrm{~s}$ the result will be the same and at a temperature of $45^{\circ} \mathrm{C}$ harmful effects will occur after $5 \mathrm{~h}$.

In general, the literature shows that if the temperature rises above $55^{\circ} \mathrm{C}$ for a period of longer than one-half a minute, serious damage will be done to the bone, which may take several weeks to fully recover.

Some previous attempts have been made to measure temperature when drilling bone by inserting thermocouples adjacent to the drill as it progressed into the hole. Krause [9] attempted to measure temperature when drilling bone by cementing a $\phi 1.07 \mathrm{~mm}$ copper-constantan thermocouple into a hole previously drilled from the endoesteal surface. The drill under test approached the thermocouple along the same axis from the periosteum surface, stopping just short of it. This gave an indication of the temperature of the cutting edges of the drill as they approached the thermocouple. No irrigation was used during the drilling. As would be expected, indifferent results were obtained using this method.

Methews [10] and Methews and Green [11] cemented thermocouples into four separate $\phi 0.7 \mathrm{~mm}$ holes drilled about a centre at radii of 2.5, 3.0, 4.0 and $5.0 \mathrm{~mm}$. They then drilled a $\phi 4 \mathrm{~mm}$ hole through the centre and measured the temperature from each thermocouple.

Their findings showed that cutting speed had very little effect on temperature change above $55^{\circ} \mathrm{C}$ but that the force applied to the drill caused a much greater temperature increase.

Insofar as can be established from the literature, attempts at temperature measurement when drilling cortical bone have been carried out by placing thermocouples into the bone at given distances from the drilling area. Indifferent and sometimes contradictory results have been achieved using these methods.

It is the opinion of the present authors that because of the poor thermal conductivity of bone, its structural inconstancy and the great difficulty in modelling for heat-transfer purposes, embedding thermocouples in the bone adjacent to the drilling operation is not a satisfactory method of measuring the temperature effects. 


\subsection{Aim of the research}

The aim of the research was to accurately establish the temperature at the cutting edge when drilling both human and animal bone and to examine the effect this increase in temperature would have on the physical aspects of the bone structure with particular emphasis on the ability of the bone to retain a surgical self-tapping screw.

This research was carried out as part of an overall investigation into the mechanics of drilling bone [12].

\section{Methodology}

Research by Hillery and Shuaib [3] has established that the optimum point angle for drilling bone lies in the range of $70-80^{\circ}$ and that a rake angle in the region of $20-30^{\circ}$ sufficiently clears the chips and also gives the lowest thrust force without 'grabbing' on drill break-through. This drill point geometry was used for the research on temperature measurement at the drill point.

\subsection{Bone collection and preparation}

Drilling tests were carried out on both human and animal bone.

A distal ulna, the heads of femurs and many other pieces of cortical and metaphyseal bone were collected from two separate orthopaedic operating theatres. Some of the experiments were performed on fresh bone within $24 \mathrm{~h}$ of their removal, the remainder of the bone being immediately frozen to $-18^{\circ} \mathrm{C}$ and stored in a refrigerator until required, as recommended by Sedlin and Hirsch [13].

In the case of animal bone the specimens were obtained from a local abattoir and were from 14 months old cattle. The tibia was chosen as a suitable long bone for drilling, the thickness of the cortical bone of the specimens ranging from 7 to $9 \mathrm{~mm}$.

A special container that was capable of holding 21 of normal saline solution was fitted with a heating element to heat the fluid within the container. A thermostat was also fitted which gave a precise temperature control of the fluid to $\pm 0.5 \mathrm{~K}$.

The solution was maintained at $37^{\circ} \mathrm{C}$ to simulate body temperature. During the thawing process the specimen was sealed in a waterproof cover in order to prevent the absorption of fluid by the specimen during the process. The specimens were then slowly thawed and when ready they were removed from the container. At this point all the soft tissue and the periosteum was removed from the specimens using a surgical knife. A standard orthopaedic saw was used for cutting the specimens. The bovine tibiae were cut first at each end at the junction of diaphysis with the metaphyseal bone. The metaphyseal bone was then discarded. The diaphyseal bone was cut longitudinally into halves. These pieces were than cut into lengths of $3 \mathrm{~cm}$ with an average width of $2 \mathrm{~cm}$.

\subsection{Bone hardness}

There is a great variation in the hardness of the different bones in a particular body and there can be a great variation in the hardness of a particular bone due to the age, gender, race or diet of the person. This variation will cause a consequent variation in the thrust, torque and power values of a particular drilling operation. Therefore the hardness of all of the bone used was established in order to compare 'like with like.' It was difficult or impossible to use normal hardness testing machines such as the Brinell or Vickers instruments, but a simple hand-held Barber Coleman Impresser model 934-1, which was capable of operating over very small areas, gave accurate and consistent results when compared with results from a Rockwell-H machine on samples large enough to be tested using both machines.

The hardness values were taken at short intervals across the thickness of the bone and also values were taken along the bone surface. Bones which had similar hardness characteristics were grouped and used later in drilling tests.

\subsection{Design for drilling}

It was decided that the most efficient method of measuring the temperature at the cutting edge was to locate a thermocouple as close as possible to the point within the drill-bit itself. The reasoning for this was that stainless steel is a much better conductor of heat than bone, having a thermal conductivity of $14 \mathrm{~J} / \mathrm{msK}$, and it was considered that better results could be obtained than those previously available.

\subsubsection{Drill-bit design}

In order to place the thermocouple in the drill-bit as close as possible to its cutting edge, surgical stainless steel piping of $4.5 \mathrm{~mm}$ outside diameter having a bore of approximately $1 \mathrm{~mm}$ was selected to make five separate drill-bits. This steel tube was ground to a diameter of $3.2 \mathrm{~mm}$ and fluted to a helix angle of $23^{\circ}$, as for normal twist drill manufacture. The tip of each tube was closed by welding using a filler rod of the same stainless steel material. Three of the drill-bits were then ground to a $90^{\circ}$ point angle and one each to $70^{\circ}$ and $80^{\circ}$. Previous research [3] by the authors has shown that these geometries are the most efficient for the drilling of bone.

A K-type insulated thermocouple was placed and 'bedded' inside the drill and its leads were then glued along the drill barrel. The wall thickness at the cutting edge was in the region $0.5-0.7 \mathrm{~mm}$.

The system was calibrated by placing the drill-bit and a standard thermocouple into a container of water that was heated in steps of $5 \mathrm{~K}$ to boiling point. The temperature response time for the drill-bit compared to the thermocouple was, at most, $3 \mathrm{~s}$ throughout the range. 


\subsubsection{The drilling machine}

The machine used for drilling was a modified Emco milling machine with an inverter fitted to the spindle motor, which gave a speed range from approximately 50-2500 rev/min. The spindle speed reading was detected by a specially fitted digital read-out meter that was 'switched' by a small proximity magnet attached to the top of the spindle.

A small drilling machine chuck was used for holding the drill-bit. The chuck in turn was rotated by the milling machine collet. The chuck also had a hole drilled through its shank to allow for the lead wires from the thermocouple to be threaded through it. These lead wires were then connected to an electrical 'connector block,' the other side of which was connected to a pair of brass slip rings fitted at the top of the machine spindle. A pair of brushes was then used to make electrical contact with a digital read-out pyrometer capable of reading to $\pm 0.1 \mathrm{~K}$.

An infinitely variable DC servo motor was connected to the feed lead-screw through a toothed belt and reduction gear for precisely controlling the feed rate from 1 to $200 \mathrm{~mm} / \mathrm{min}$.

\subsubsection{The drilling dynamometer}

All drilling took place by clamping the sample bone onto the work table of a sensitive drilling dynamometer [14] that was capable of taking pieces of a length of up to $300 \mathrm{~mm}$ and height $25 \mathrm{~mm}$. This dynamometer measured both the torque and the thrust forces generated. The active elements of the measuring cantilevers were Kwoya KFD-2-D16-L30-type strain gauges with pre-attached lead wires in a half bridge circuit with separate identical compensation gauges. The dynamometer was calibrated by physically applying different known load and torque values.

The general machine arrangement is shown in Fig. 2.

\subsection{The drilling procedure}

The thawed bones were clamped to the work table of the dynamometer and then drilled. At least two holes were drilled for each speed and feed. Occasionally, wedging of the drill-bit occured due to the chips not clearing along the flutes. This happened particularly in the high speed drilling of bovine cortical bone. In one case this wedging resulted in the fracture of the drill-bit. Due to this, if there was any major variation from one piece of data to the next, the drill was changed and the experiment was repeated to verify the result.

The speeds used were $400,600,800,1000,1200,1400$, 1600,1800 and $2000 \mathrm{rev} / \mathrm{min}$. These were chosen in order to go below and above the speeds recommended in the literature for the drilling of bone.

The feeds ranged from 40 to $60 \mathrm{~mm} / \mathrm{min}$ and generally settled at $50 \mathrm{~mm} / \mathrm{min}$. These feeds were chosen arbitrarily, since in orthopaedic practice the feed rate varies from surgeon to surgeon and in the case of a particular

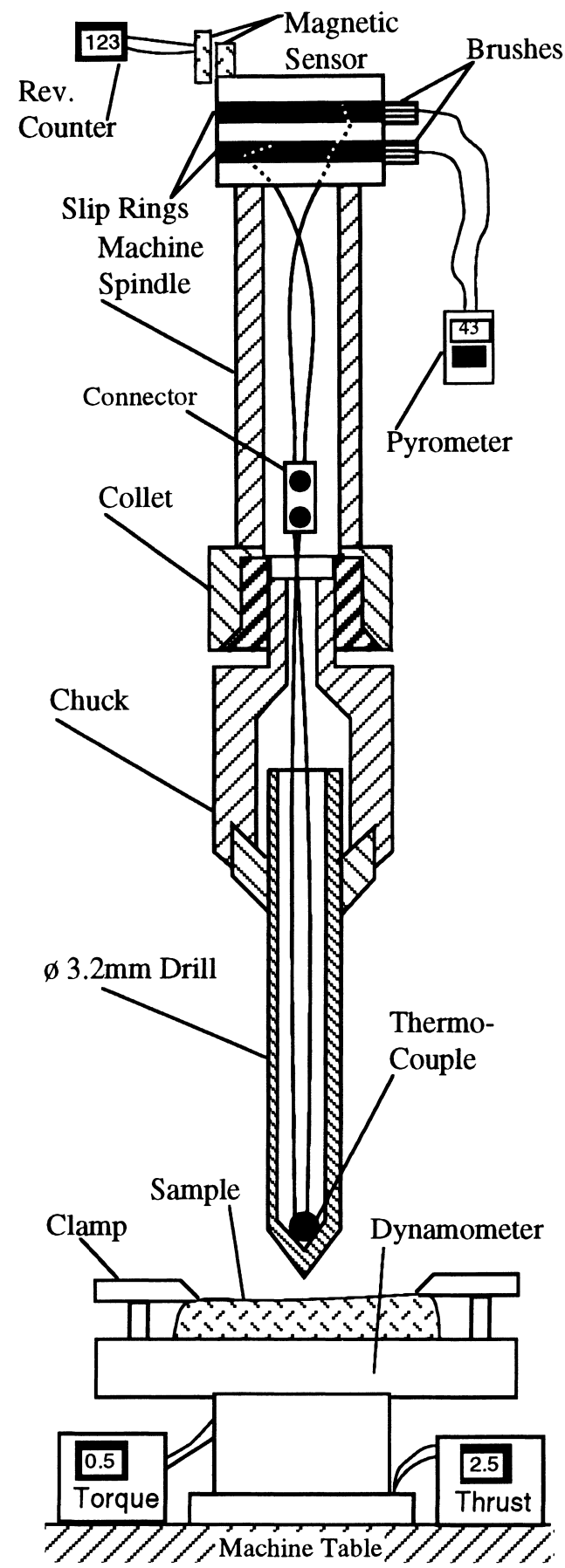

Fig. 2. Drill and chuck assembly for temperature measurement.

surgeon there will also be a variation, since the drill is hand-held.

\section{Temperature variation in drilling bone}

Some holes were drilled using $70^{\circ}, 80^{\circ}$ and $90^{\circ}$ point angles to ascertain the effect of point geometry on temperature. It was found that temperature variation across the three drills was not significant. 


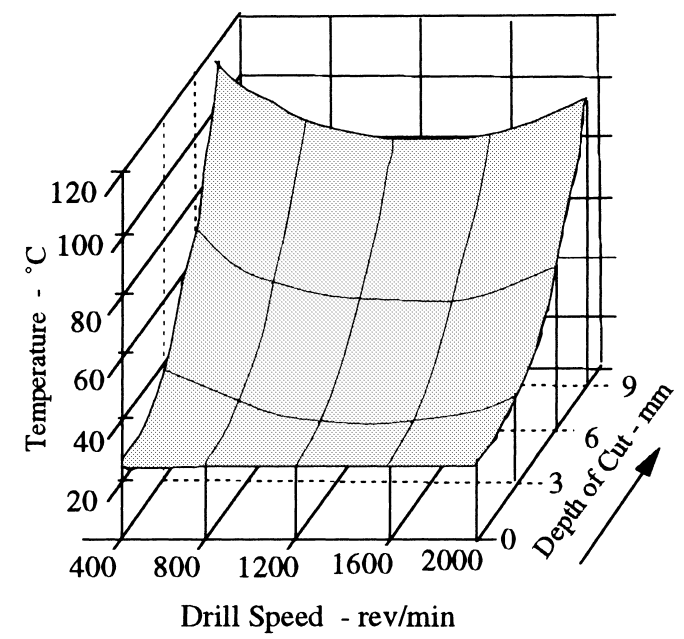

Fig. 3. Temperature vs. speed and depth when drilling bovine cortical bone.

Since it was easier to manufacture drill-bits with a $90^{\circ}$ point angle, this geometry was used to drill over 100 holes, without coolant, to a depth of up to $9 \mathrm{~mm}$ in steps of $3 \mathrm{~mm}$ for bovine bone and to $6-7 \mathrm{~mm}$ for human bone. The drilling was performed at a room temperature of $26^{\circ} \mathrm{C}$.

Fig. 3 shows the temperature variation for bovine cortical bone for a variety of speeds and a variety of depths of hole. The feed was set at $50 \mathrm{~mm} / \mathrm{min}$.

Considering the first drilling series to a depth of $3 \mathrm{~mm}$ the average temperature variation ranged from $38^{\circ} \mathrm{C}$ at $400 \mathrm{rev} /$ min down to slightly above room temperature at $1300 \mathrm{rev} /$ min and rising again to $29^{\circ} \mathrm{C}$ at $2000 \mathrm{rev} / \mathrm{min}$. When the bone was drilled to a depth of $9 \mathrm{~mm}$ there was an increase in temperature, which ranged from $102-117^{\circ} \mathrm{C}$ as the speed ranged from 400 to $2000 \mathrm{rev} / \mathrm{min}$.

Fig. 4 shows a similar temperature plot for human bone using the same speeds and feed. The temperature recorded whilst drilling to a depth of $2-3 \mathrm{~mm}$ at room temperature of $26^{\circ} \mathrm{C}$ and at a drill speed of $400 \mathrm{rev} / \mathrm{min}$ gave a temperature reading of $36^{\circ} \mathrm{C}$. In the speed range of 600-2000 rev/min the temperature reading did not reach greater than $28^{\circ} \mathrm{C}$, but as the depth of the hole was increased to 5-6 $\mathrm{mm}$ the temperature also increased to $80^{\circ} \mathrm{C}$ at $400 \mathrm{rev} / \mathrm{min}$. As the speed approached $1200 \mathrm{rev} / \mathrm{min}$ at this depth, the temperature gradually dropped to $68^{\circ} \mathrm{C}$ and rose again to approximately $75^{\circ} \mathrm{C}$ with an increase in speed to $2000 \mathrm{rev} / \mathrm{min}$.

It is obvious that as the drill-bit travels further into the bone there is an increase in temperature due to the inability of the bone to conduct the heat generated away from the point.

Earlier research by the authors [3] has shown that when using the same drill-bit diameter and geometry there is an exponential falling-off of the cutting torque from $14.5 \times 10^{-3} \mathrm{Nm}$ at $400 \mathrm{rev} / \mathrm{min}$ to an asymptote of $10 \times 10^{-3} \mathrm{~N} \mathrm{~m}$ at $2000 \mathrm{rev} / \mathrm{min}$.

There was a corresponding falling-off of the thrust force from $48 \mathrm{~N}$ at $400 \mathrm{rev} / \mathrm{min}$ to an asymptote $23 \mathrm{~N}$ at

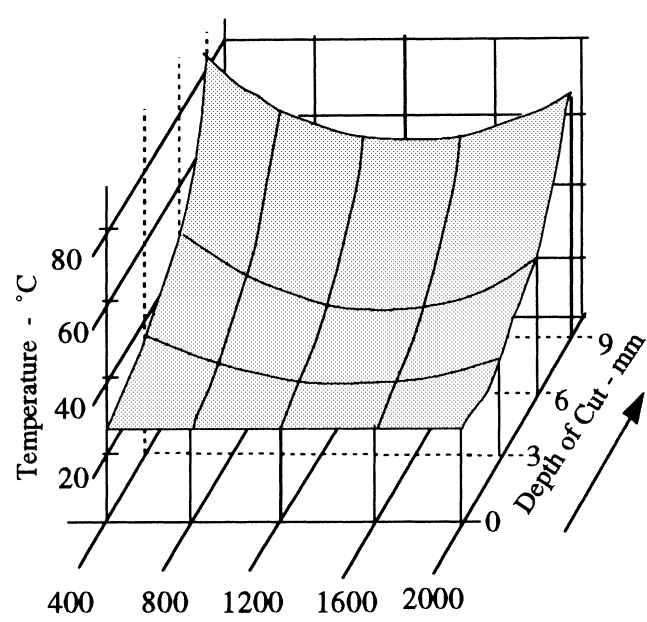

Drill Speed - rev/min

Fig. 4. Temperature vs. speed and depth when drilling human bone

$2000 \mathrm{rev} / \mathrm{min}$. These trends are shown in Figs. 5 and 6, respectively.

It is suggested that the temperature drop in the cutting range from 400 to $1200 \mathrm{rev} / \mathrm{min}$ reflects the reduction in the cutting torque and thrust parameters, which in themselves more than compensate for the increase in heat generation due to the higher speeds. The slight increase in temperature over the speed range of 1200-2000 rev/min probably could be attributed to the drop-off in the rate of torque and thrust change, which were not sufficient to compensate for speed change, since the torque and thrust force at $1200 \mathrm{rev} / \mathrm{min}$ was only $10.7 \times 10^{-3} \mathrm{~N} \mathrm{~m}$ and $25 \mathrm{~N}$, respectively.

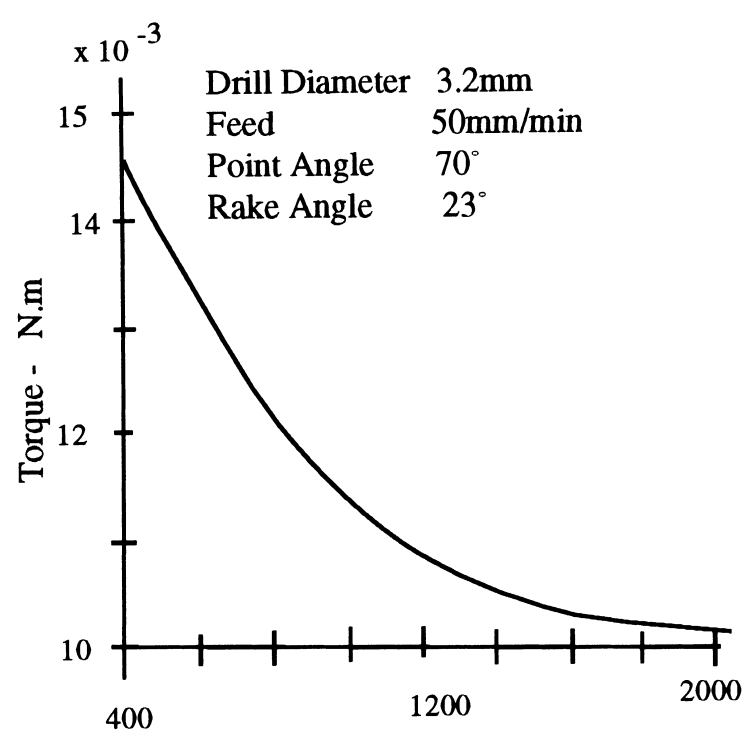

Speed - rev/min

Fig. 5. Torque-speed relationship for the drilling of bovine cortical bone. 


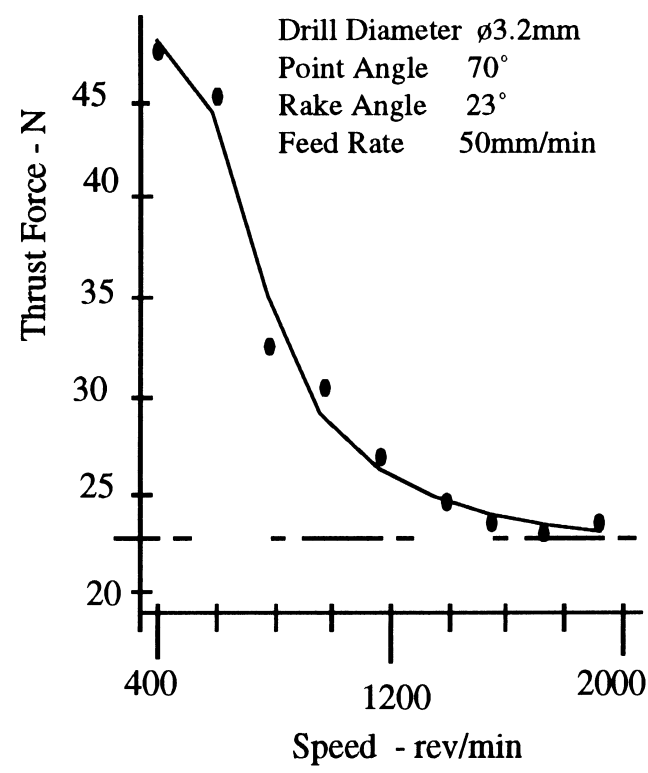

Fig. 6. Thrust-speed relationship for the drilling of bovine cortical bone.

\section{Examination of the holes}

For the bovine cortical bone, 10 of the holes that had been drilled to a depth of $9 \mathrm{~mm}$ were examined under electron and optical microscopes. The holes produced were cut longitudinally and the surface of each hole was cleaned gently with a cloth and a mild jet of air in order to remove any debris from its surface. These specimens were then left to partially dry at $37^{\circ} \mathrm{C}$ for 3 days. They were then exposed to a vacuum after which they were sputtered with gold and examined on a Joel JSM 840 scanning electron microscope. From this examination it was noted that there were a number of different micro-fractures, which had various shapes made up of: (i) irregular lines; and (ii) dendritic shapes. Circular markings were also noted along the diameter of the hole. These were produced by the rubbing of the drill bit and the trapped chips, which embedded themselves into the hole surface.

However, the depth of burning or rubbing damage was comparatively shallow and was only in the region of $0.2-$ $0.3 \mathrm{~mm}$ at the section where the drill recorded a temperature of $115^{\circ} \mathrm{C}$.

When examined under the optical microscope some of the holes appeared to be slightly burned, but this appearance could also have been due to the rubbing of the drill behind the point as it proceeded into the hole. Whilst drilling there was also a faint smell of burning. A similar examination was carried out on a number of holes drilled in the human bone. In this case, probably due to the lower temperatures, it was not possible to detect any evidence of burning.

It is reasonable to assume that this lack of damage to the hole surface at temperatures that would have been previously considered to be very high is due to the heat insulation characteristics of bone. It also shows that placing thermocouples within the bone, adjacent to the drilling surface, as a means of measuring temperature is not a satisfactory solution to the problem of temperature measurement due to the insulating effect of the bone itself and that if temperatures greater than $45^{\circ} \mathrm{C}$ are reached by this method, then the temperature at the drill-bit cutting edge must be considerably higher with consequent severe damage to the bone surface of the hole.

\subsection{Pull test for self-tapping screws}

In order to establish the holding force of the $25 \mathrm{~mm}$ long, $\phi 4.5$ self-tapping screws, $10 \phi 3.2$ holes were drilled in a fresh bovine tibia. All of the screws were driven by the same person using a hand-held screw driver, as would be the case in a normal surgical procedure. All of the holes were sufficiently close to each other to give consistent bone surface hardness. The same speeds, ranging from 400 to $2000 \mathrm{rev} / \mathrm{min}$, were selected as already used for the temperature tests and all holes were drilled to a depth of $9 \mathrm{~mm}$.

A 'pull' test was devised [15] where a standard sensitive digital read-out 'Pull/Push' dynamometer was secured to the chuck of a drilling machine and a special collar was attached to the other end that could fit easily under the head of the screw. A tensile load could then be applied to the head of the screw by raising the chuck of the drilling machine. The force required to withdraw the screw was then read off from the dynamometer. Fig. 7 shows the 'pull test' arrangement.

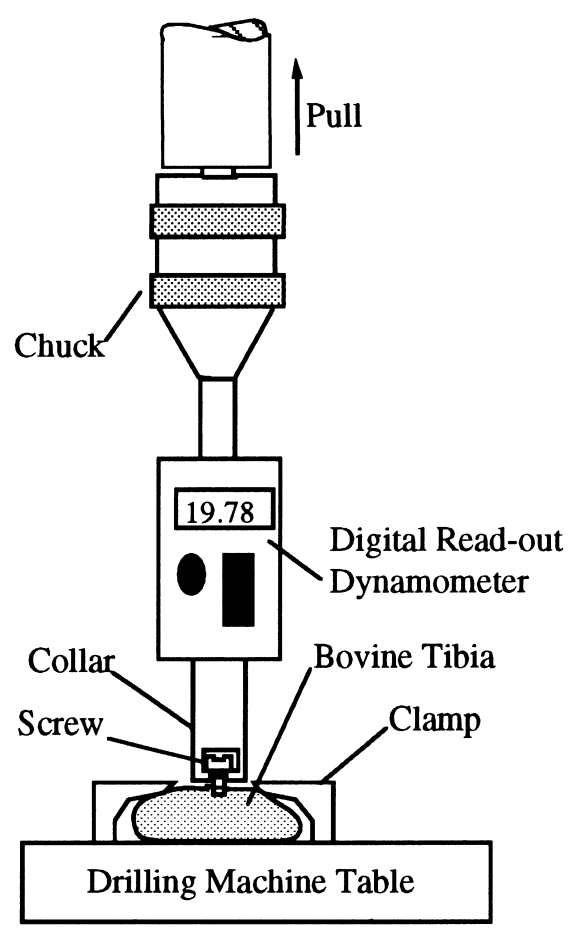

Fig. 7. Screw pull test. 
The pull test for all 10 holes ranged between 350-360 N and it was not possible to detect a trend due to cutting speed or temperature effect.

\section{Conclusions}

There was no significant difference noted in the temperatures produced when drilling with tools with point angles of 70,80 or $90^{\circ}$ with a $23^{\circ}$ positive rake angle.

The temperature increased as the depth of the hole increased. The temperature generated when drilling a bovine bone was higher than that produced when drilling human bone. This is to be expected, since the bovine bone is much harder and the depth of the cortical bone is greater than that of the human bone. The cortical specimen thickness for the bovine bone was 7-9 $\mathrm{mm}$ and that of the human ulna 3$5 \mathrm{~mm}$.

Speeds of 800-1400 rev/min should be used when drilling with a $\phi 3.2 \mathrm{~mm}$ drill-bit to provide the best cutting conditions and maintaining temperatures at a manageable level.

The temperature developed at the drill cutting edge, whilst high relative to previously suggested limits, does not in fact seriously damage the effective depth of bone thread used in securing surgical self-tapping screws.

\section{Acknowledgements}

The authors wish to thank Mohawk Europe Ltd., manufacturers of specialist twist drills, Shannon, Ireland, for their technical and financial contribution to the project.

\section{References}

[1] C.H. Jacobs, A study of the bone machining process, drilling, J. Biomechanics 9 (1976) 343-349.

[2] S. Saha, Surgical drilling and design of an improved drill, J. Biomechanics 104 (1982) 245-252.

[3] M.T. Hillery, I. Shuaib, The drilling of bone using guide wires and twist drills, IMC-13, Ireland, (1996) pp. 33-42.

[4] R. Huskies, Some fundamental aspects of human joint replacement, Acta Orthop. Scand. 185 (1979) 62-63.

[5] A. Lansari, Effects of torque and heat generation during direct cortical trochar tipped pin insertion, Annals of Biomechanical Eng. 19 (1991) 6411.

[6] J. Lundskog, Heat and bone tissue, Scand. J. Plastic and Reconstructive Surgery, Sup. 9 (1972).

[7] A.R. Mortiz, F.C. Henrique, Studies of thermal injuries, II, Am. J. Pathol. 23 (1947) 695.

[8] A.R. Mortiz, F.C. Henerique, The relative importance of time and surface temperature in the causation of cutaneous burns, Am. J. Physiol. 23 (1947) 695-719.

[9] W.R. Krause, Temperature elevations in orthopaedic cutting operations, J. Biomechanics 15 (1985) 267-275.

[10] L.S. Methews, Temperature measured in human cortical bone when drilling, J.B.J.S. 54A (1972) 297-308.

[11] L.S. Methews, C.A. Green, The thermal effects of skeletal fixationPin insertion in bone, J.B.J.S. 66A (7) (1984).

[12] I. Shuaib, The drilling of bone using guide wires, twist drills and cutters, Ph.D. thesis, University of Limerick, 1996.

[13] E.D. Sedlin, C. Hirsch, Factors affecting the deformation of the physical properties of femoral cortical bone, Acta Orthop. Scand. 37 (1966) 29-48.

[14] W.P. Hennessy, M.T. Hillery, The design and manufacture of a drilling dynamometer for drilling Kevlar-49 reinforced composites, Proc. IMC-8, Ireland, (1991) pp. 803-816.

[15] I. Shuaib, M.T. Hillery, Forces generated in guide wires when drilling human bone, Proc. Inst. Mech. Eng., Part H, J. Eng. in Medicine 209(H3) (1995) 157-162. 